DOI: $10.14451 / 2.142 .41$

\title{
К ВОПРОСУ О ФИНАНСИРОВАНИИ ИНВЕСТИЦИОННЫХ ПРОЕКТОВ В РАМКАХ ГОСУДАРСТВЕННО-ЧАСТНОГО ПАРТНЕРСТВА (ФИНАНСОВО-ПРАВОВЫЕ И ПРОБЛЕМНЫЕ АСПЕКТЫ)
}

\author{
(c) 2020 Терехова Елена Владиславовна \\ кандидат юридических наук \\ Российский государственный университет правосудия, Россия, Москва \\ E-mail: Ter_finlaw@mail.ru
}

Данная статья посвящена вопросам финансирования и налогообложения инвестиционных проектов в рамках государственно-частного партнерства, муниципально-частного партнерства. В статье анализируются финансовые - правовые проблемы реализации инвестиционных проектов, а также формулируются предложения, направленные на их решение.

Ключевые слова: инвестиционный проект, государственно-частное партнерство, муниципальночастное партнерство, субсидия, проектное финансирование, налогообложение.

Одной из характерных особенностей института государственно-частного партнерства (ГЧП), муниципально-частного партнерства (МЧП) [1] выступает реализация публичных функций государства через привлечение частного потенциала в финансирование инфраструктурных и иных проектов.

ГЧП (МЧП) выступает институтом равноправного взаимодействия государства и представителей бизнес-кластера. Вместе с тем государственное участие обеспечивает особые гарантии участникам проектов, позволяет спрогнозировать сроки сдачи объектов и гарантирует правовую защиту представителям бизнес структур, несмотря на то, что в данных отношениях стороны признаются равноправными.

С учетом анализа действующего законодательства финансирование объектов ГЧП (МЧП), а также эксплуатации, технического обслуживания осуществляется за счет предоставления субсидий из бюджетов бюджетной системы Российской Федерации (Федеральный закон от 13.07.2015 г. N 224-Ф3 «О государственночастном партнерстве, муниципально-частном партнерстве в Российской Федерации и внесении изменений в отдельные законодательные акты Российской Федерации» [2] (Федеральный закон о ГЧП (МЧП))).

Вместе с тем, отсутствие определения субсидий в БК РФ [3] негативно отражается на практике в части их распределения, назначения, механизма долевого финансирования и других характеристик трансфертного инструмента (ст. 78 БК РФ определяет цели предоставления суб- сидий юридическим и физическим лицам).

Кроме того, система источников финансирования инвестиционного проекта включает собственные средства инвестора, а также привлеченные средства (Федеральный закон от 25.02.1999 г. N 39-Ф3 «Об инвестиционной деятельности в Российской Федерации, осуществляемой в форме капитальных вложений» [4] (далее - Закон об инвестиционной деятельности в форме капитальных вложений)).

В основном проекты ГЧП (МЧП) предполагают привлечение заемных источников с использованием схем проектного финансирования.

Проектное финансирование характеризуется специфическим способом обеспечения возвратности вложений, в основе которого лежат инвестиционные качества самого проекта и полученной прибыли от его реализации. Особенностью данной формы финансирования является синтез различных видов капитала, в частности банковского, коммерческого, государственного, международного, что выступает несомненным плюсом проектного финансирования, в отличие, например, от программно-целевого финансирования. При этом присутствует возможность осуществить рассредоточение риска между участниками инвестиционного проекта. Кроме того, с учетом проектного финансирования реализуются долгосрочные проекты через механизмы «длинных» кредитных линий, что оказывает положительный эффект для инвестиционного процесса в целом. Проектное финансирование предполагает создание проектной компании (CПK/SPV). Однако в связи с созданием такой 
компании по российскому законодательству возникает ряд проблем, в основном из-за невозможности ограничить ее правоспособность.

В финансировании проектов ГЧП, используя различные правовые средства, государство может участвовать в качестве инвестора с применением программно-целевого метода финансирования (ст. 11 Закона об инвестиционной деятельности в форме капитальных вложений)). При этом инвестиционные проекты могут претендовать на получение средств инвестиционного фонда (ст. 179.2 БК РФ).

Помимо средств бюджетов различных уровней суверенные фонды инвестиционной направленности могут стать одним из финансовых источников осуществления инфраструктурных проектов [5]. Так, в настоящее время финансирование проектов ГЧП может быть осуществлено за счет средств Фонда национального благосостояния [6] и (или) пенсионных накоплений на возвратной основе. Отметим, что инициатором ГЧП - проекта, который имеет в качестве софинансирования средства Фонда национального благосостояния и (или) пенсионных накоплений, может быть исключительно российский инвестор. Оценка целесообразности финансирования проекта за счет указанных средств осуществляется на основании результатов оценки стратегического (например, достижение целей отраслевой или региональной стратегии, целевых показателей государственных программ РФ) и комплексного (например, оценка коммерческой эффективности проекта, кредитная устойчивость инвестора, социально-экономическая оценка проекта) обоснований инвестиционного проекта.

Вместе с тем источником финансирования проектов (государственные инвестиции) выступают средства государственных организаций, корпораций и компаний. Например, Внешэкономбанк [7] осуществляет свою деятельность путем предоставления кредитов, займов, осуществления лизинговых операций и финансирования на возвратной основе в иных формах, выдачи гарантий и поручительств, участия в уставных капиталах хозяйственных обществ, гарантийной поддержки экспорта. Дочерним обществом Внешэкономбанка является управляющая компания Российский фонд прямых инвестиций (далее - РФПИ), созданный для соинвестирования проектов с крупнейшими институциональными инвесторами мира.
Финансирование проекта за счет частного инвестора по общему правилу реализуется в правовых формах концессионных соглашений и соглашений о разделе продукции. В указанных соглашениях вклад публичного партнера частному заключается в предоставлении недвижимого имущества и права на его эксплуатацию в течение определенного соглашением срока или исключительного права на поиски, разведку, добычу минерального сырья на участке недр, указанном в соглашении, и на ведение связанных с этим работ. Иные правовые формы осуществления ГЧП, в частности, предусмотренные региональными законами о ГЧП, также не предполагают участия государства в финансировании проектов ГЧП, определяя вклад публичного партнера в проект в виде недвижимого имущества, в т.ч. земельного участка, различных налоговых льгот, иных форм государственной поддержки.

Особое место в финансирования инвестиционных проектов занимает налогообложение доходов и бухгалтерский учет средств организации -инвестора. Положение по бухгалтерскому учету «Учет государственной помощи» ПБУ 13/2000»[8] регламентирует организацию учёта бюджетных средств, предоставляемых коммерческим организациям (за исключением кредитных организаций), устанавливаются правила формирования данных о получении и использовании помощи со стороны государства [9]. Данные о государственном субсидировании формируются вне зависимости от видов предоставленных ресурсов (в виде денежных средств или (и) в виде ресурсов, отличных от денежных средств).

Получателям бюджетных средств целевого финансирования важно соблюдение названного ПБУ 13/2000, в связи с тем, что ненадлежащий учет таких средств может повлечь неблагоприятные последствия в сфере налогообложения.

Кроме того, следует указать, что в законодательстве отсутствует определение целевого финансирования. Целевое финансирование можно определить как предоставление денежных ресурсов от разных субъектов экономической деятельности на строго обусловленные цели.

Порядок налогообложения, в том числе на средства финансирования инвестиционных проектов, регламентирован Налоговым кодексом Российской Федерации (НК РФ) [10]. Тем не менее, в связи с тем, что имели место изменения законодательства, методические указания к ста- 
тьям налогообложения отсутствуют, неясно интерпретируются, в частности это касается учета налога на добавленную стоимость [11].

Не учитываются в налогооблагаемых базах налогов на прибыль доходы от поступающего целевого финансирования, однако при обращении к налоговому законодательству (п.п. 14 ч. 1 ст. 251 НК РФ), можно увидеть, что для юридических лиц допускается отнесение к указанным доходам только некоторые виды средств. Например, средства, которые предоставляются в виде инвестиций, полученных при проведении инвестиционных конкурсов (торгов) в установленном законом порядке. Кроме того, все остальные виды, перечисленные в указанной статье, относятся в большей степени к казенным, бюджетным учреждениям, некоммерческим организациям, но при этом к частному сектору можно отнести всего несколько видов.

Особенностью налогообложения финансирования инвестиционных проектов является то, что ст. 251 НК РФ обязывает вести раздельный учёт доходов / расходов, которые получены ими в рамках финансирования. В противном случае средства отнесут к налогооблагаемой базе [12].

Статья 256 НК РФ указывает, что имущество, которое приобретено или создано за счет бюджетных средств финансирования не амортизируется. В таких случаях возникает расхождение организации бухгалтерского и налогового учёта, т.к. в бухгалтерском учёте имущество, которое получено или создано за счёт средств финансирования, амортизируется.

Рассматривая налог на добавленную стоимость, можно отметить, что налоговое законодательство не содержит правил, регламентирующих правоотношения между данным налогом и имуществом, услугами, работами, полученными посредством целевого финансирования. Ранее Приказ МНС РФ от 20.12.2000 г. № БГ - 3-03 / 447 вносил методические рекомендации по применению 21 главы НК РФ и содержал положения по этому вопросу. Однако в настоящее время указанный приказ не действует. При этом новые методические рекомендации в данной области отсутствуют, что вызывает финансовые трудности по учёту НДС при целевом финансировании.

Следует отметить приоритетное значение специальных налоговых режимов и налоговых льгот, которые способствуют привлечению инвесторов для финансирования инвестиционных проектов.
В основном региональное законодательство закрепляет особенности налогообложения участников ГЧП, за исключением положений гл. 26.4 НК РФ.

Согласно ст. 380 НК РФ ставки налога на имущество организаций устанавливаются законами субъектов Российской Федерации и не могут превышать 2,2\%. Например, в Республике Саха (Якутия) установлена пониженная ставка налога на имущество организаций в размере 1,1\% для организаций, основным видом которых является деятельность по производству, передаче и распределении пара и горячей воды (тепловой энергии), в отношении объектов жилищного фонда и инженерной инфраструктуры жилищно-коммунального комплекса при условии заключения ими концессионных соглашений в сфере теплоснабжения [13].

Следует учесть, что не только на региональном, но и на муниципальном уровне принимаются попытки привлечения частных инвесторов в приоритетные сферы с помощью различных мер поддержки МЧП. Например среди возможных форм муниципальной поддержки МЧП в городе Люберцы, осуществляемых в соответствии с федеральным законодательством и законодательством Московской области, можно выделить: предоставление налоговых льгот в соответствии с НК РФ и нормативными правовыми актами города Люберцы; установление понижающего коэффициента к установленным базовым ставкам арендной платы за пользование имуществом, находящимся в муниципальной собственности города Люберцы; согласование предоставления отсрочек и рассрочек по уплате местных налогов; предоставление бюджетных инвестиций [14].

Все же законодательство субъектов Российской Федерации и муниципальных образований регулирует некоторые налоговые стимулы и ограничивает возможность применения (гибкое) фискальных методов регулирования.

Единственный специальный налоговый режим, установленный для сторон ГЧП, распространяется на деятельность по поиску, разведке и добыче минерального сырья на территории Российской Федерации, а также на континентальном шельфе и (или) в пределах исключительной экономической зоны Российской Федерации. Глава 26.4 НК РФ определяет все элементы данного режима и сферу его применения совместно с Федеральным законом от 30.12.1995 г. № 225- 
Ф3 «О соглашениях о разделе продукции».

Действующее региональное законодательство не в достаточной степени отражает возможности налогового регулирования совместной деятельности в рамках партнерств. Закрепление налоговых льгот и преференций при заключении конкретных соглашений не представляется той формой правового регулирования, которая стала бы наиболее эффективной и корректной в действующей системе законодательства по ряду причин: «договорная» льгота может рассматриваться как дискриминация по отношению к другим случаям исполнения обязательств по соглашению с государством; отсутствие представлений у частного инвестора об экономических выгодах заключения подобных соглашений на самом начальном этапе принятия решений может стать фактором, свидетельствующим далеко не в пользу участия в проекте ГЧП; частный характер предоставления налоговых льгот и освобождений может стать основой для экономического или правового анализа, носящего лишь такой же частный характер.

Анализ опыта деятельности в рамках ГЧП в России показывает, что дифференцировать специальные налоговые режимы целесообразно по видовому признаку с учетом классификации видов экономической деятельности. Каждый из режимов должен быть ориентирован на создаваемый объект и его отраслевую принадлежность. В частности, специальный режим следует разработать для участников проектов в следующих сферах: жилищное строительство; транспортная инфраструктура; объекты в сфере обращения с отходами; здравоохранение; образование; коммунальное хозяйство и т.д. Рассматривая действующие специальные налоговые режимы, заметим, что в отдельных случаях они предполагают замену нескольких налогов единым обязательным платежом (при упрощенной системе налогообложения, едином сельскохозяйственном налоге и др.).

Отмена ряда налогов в пользу применения одного закреплена ст. 346.11 п. 3, ст. 346.26 п. 4 НК РФ. В других же случаях предполагается лишь частичная трансформация общего подхода к налогообложению, как в специальном режиме для соглашений о разделе продукции (гл. 26.4 НК РФ). Упомянутый режим вводит специальные нормы по налогу на добычу полезных ископаемых, оставляя общие правила исчисления и уплаты налога на прибыль организаций, НДС.
Следует отметить, что НК РФ предусматривает следующие виды налоговых льгот по налогу на прибыль (ст. 284 НК РФ): возможность снижения ставки налога на $4.5 \%$ (т.к. минимальная ставка - 13,5\%); пониженная ставка для резидентов особых экономических зон; ставка 0\% для организаций, осуществляющих образовательную и медицинскую деятельность.

Стоит согласиться с мнением Боровикова Е. В. [15] о том, что наиболее целесообразным стал бы налоговый режим, сочетающий уже установленные налоги (а не единый, заменяющий совокупность платежей), но уплачиваемые в ином особом порядке.

Таким образом, прослеживается взаимосвязь в развитии института ГЧП (МЧП) с комплексом мер по улучшению финансово-правового климата для бизнес-партнеров в рамках инвестиционного процесса. При этом значение приобретает необходимость оценки экономической целесообразности проекта, включая вопросы (источники, формы, методы) его финансирования еще на стадии планирования инвестиционного проекта.

В качестве меры, направленной на решения финансовых трудностей, предлагается внедрение механизма резервного денежного фонда под конкретный инвестиционный проект, из которого будут поступать увеличенные ассигнования контрагенту при возникновении нестабильной экономической ситуации. Вместе с тем, следует указать, что со стороны частных партнеров также могут быть недобросовестные действия, например, путем увеличения сроков сдачи объектов, завышения сумм издержек в процессе реализации проекта и т.д. В этой связи, необходимо внедрять возможные механизмы страхования при неблагоприятном развитии инвестиционных сделок (по договору ГЧП, инвестиционному контракту) с частным сектором путем создания специального фонда в сфере страхования рисков убытков как государственного партнера, так и частного инвестора - контрагента. Здесь же важно определиться со статусом и полномочиями формируемого фонда (федеральный, региональный). Кроме того, необходимо по данному вопросу внести соответствующие изменения в законодательство о ГЧП, а также разработать соответствующее положение о таком фонде.

В заключение отметим, что основной системный недостаток правового регулирова- 
ния заключается в дублировании нормативных правовых актов в исследуемой сфере. Решение указанной проблемы представляется путем консолидации Федерального закона о ГЧП (МЧП) и Закона о концессионных соглашениях в один федеральный закон о публично-частном партнерстве (выработать единообразный подход к оценке концессий и ГЧП).

Вместе с тем, недостатки действующего Федерального закона о ГЧП (МЧП) негативное влияют на практическую сторону вопроса, что требует со стороны законодателя аналитической работы и внесения существенных изменений в данный нормативный правовой акт. Рассмотрим некоторые проблематичные вопросы.

В соответствии с п.5 ст.3 частным партнером может быть только российское юридическое лицо. Данная статья ограничивает круг участников проектов ГЧП (МЧП) в качестве частного партнера, например консорциумов. При этом, частным партнером не может быть индивидуальный предприниматель, а также иностранное юридическое лицо.

Далее, согласно ч.2 ст.5 частным партнером не может быть организация, находящаяся под прямым или косвенным контролем Российской Федерации, какого-либо субъекта РФ или муниципального образования. Указанный запрет охватывает не только участие указанных лиц в проекте ГЧП (МЧП) в качестве, собственно, частного партнера, но и всякое участие данных лиц на стороне частного партнера. Законодатель в данном случае не конкретизировал, что следует понимать под термином «участие на стороне частного партнера», хотя сделал это в ч.4 ст.5 в отношении «участия на стороне публичного партнера». Данное обстоятельство создает риск расширительного толкования данного положения правоприменительными органами.

Далее законодатель серьезно ограничил возможность привлечения в проект субподрядчиков. Часть 6 ст.5 закрепила принцип личного исполнения обязательств частного партнера частный партнер обязан исполнять обязательства по соглашению своими силами. На практике присутствует излишнее препятствие, когда в сложном инфраструктурном проекте участвует несколько компаний, привлекаемых частным партнером на субподряд для выполнения своей строго определенной функции (например, проектирование, строительство, техническое обслуживание и пр.).
Законодатель предусмотрел в ч.8 ст.5 требование о наличии у частного партнера всех необходимых в соответствии с законодательством Российской Федерации для реализации соглашения разрешений, включая лицензии на осуществление отдельных видов деятельности и свидетельство о допуске саморегулируемых организаций к выполнению предусмотренных соглашением работ. Получение лицензий, свидетельств о допуске, разрешений вновь созданной проектной компанией может быть связано с дополнительными расходами и длительным временем, отметим, данное условие может ограничивать конкуренцию между потенциальными участниками проекта.

Также очевидно, что указанная в ч.1 ст.12 формулировка объекта соглашения нуждается в существенной доработке в части того, что единичный объект недвижимости может являться самостоятельным объектом соглашения, а также того, какие сочетания объектов недвижимого и движимого имущества допустимы - каждый ли из них должен быть технологически связан с остальными, либо они могут быть связаны последовательно, могут ли какие-либо из указанных объектов недвижимого или движимого имущества не быть технологически связаны с остальными.

Часть 6 ст.7 вводит возможность передачи в залог не только прав по соглашению, как это допускалось ранее согласно ч.4 ст.5 Закона о концессионных соглашениях, но также и самого объекта соглашения. Как и в случае с залогом прав по соглашению о ГЧП (МЧП), залог объекта соглашения разрешен лишь в случае его использования в качестве способа обеспечения исполнения обязательств перед финансирующим лицом при наличии прямого соглашения, заключенного между сторонами проектного соглашения и финансирующим лицом [16]. Во-первых, Федеральный закон о ГЧП (МЧП) устанавливает отсрочку обращения взыскания на предмет залога в размере 180 дней, а во-вторых, устанавливается запрет на обращение взыскания при досрочном расторжении соглашения о ГЧП (МЧП) в связи с существенным нарушением соглашения частным партнером, что в принципе нивелирует саму цель указанного залога - защитить кредитора от возможных нарушений со стороны заемщика. Кроме того, Федеральный закон о ГЧП (МЧП) связывает использование рассматриваемого залога со значительными рисками для 
самого частного партнера. Так, ч.7 ст.7 предусматривает на случай обращения взыскания на предмет залога право его преимущественной покупки публичным партнером по цене, равной задолженности частного партнера перед финансирующим лицом, но не более чем стоимость предмета залога. Следовательно, в случае обращения взыскания финансирующее лицо, в пользу которого был установлен залог, получит причитающиеся ему денежные средства в полном объеме, а частный партнер рискует не получить ничего даже в случае, если стоимость построенного им объекта значительно превышает размер задолженности частного партнера перед финансирующим лицом. Данное положение серьезно подрывает предусмотренный принцип справедливого распределения рисков и обязательств между сторонами соглашения (ст. 4).

Как и в случае с концессионными соглашениями, Федеральный закон о ГЧП (МЧП) в числе существенных условий предусматривает срок действия соглашения (п.5 ч.2 ст.12), однако в отличие от того же Закона о концессионных соглашениях, Законом устанавливается минимальный срок действия соглашения в размере трех лет (п.3 ст.3), и при этом вместо срока действия соглашения допускается установление порядка его определения. Таким образом, не обязательно определять срок действия соглашения календарной датой или периодом времени (ст. 190 ГК РФ), иногда для обеспечения интересов частного или публичного партнера целесообразно, к примеру, установить срок строительства (реконструкции) объекта и определить, что срок действия соглашения заканчивается с истечением периода времени, который, в свою очередь, отсчитывается с даты, в которую объект будет считаться созданным.

В отличие от срока действия соглашения, в части всех иных, промежуточных сроков законодатель ввел серьезное ограничение - все промежуточные сроки реализации проекта стали существенными условиями соглашения ГЧП (МЧП). Согласно п.7 ч.2 ст.12 в отношении каждой обязанности, которая предусмотрена соглашением, должны быть предусмотрены некие «мероприятия» по ее исполнению и в отношении каждого мероприятия должны быть установлены «графики осуществления мероприятия», включающие сроки. Тем самым данное обстоятельство может отрицательно повлиять на реализацию проекта, а также приведет к его удорожанию.

\section{Библиографический список}

1. В соответствии со ст. 3 Федерального закона от 13.07.2015 г. N 224-Ф3 «О государственно-частном партнерстве, муниципально-частном партнерстве в Российской Федерации и внесении изменений в отдельные законодательные акты Российской Федерации» государственно-частное партнерство, муниципальночастное партнерство - юридически оформленное на определенный срок и основанное на объединении ресурсов, распределении рисков сотрудничество публичного партнера, с одной стороны, и частного партнера, с другой стороны, которое осуществляется на основании соглашения о государственно-частном партнерстве, соглашения о муниципально-частном партнерстве, заключенных в соответствии с настоящим Федеральным законом в целях привлечения в экономику частных инвестиций, обеспечения органами государственной власти и органами местного самоуправления доступности товаров, работ, услуг и повышения их качества. СЗ РФ. 2015. N 29 (часть I). Ст. 4350.

2. СЗ РФ. 2015. N 29 (часть I). Ст. 4350.

3. Бюджетный кодекс Российской Федерации» от 31.07.1998 г. N 145-Ф3 (ред. от 07.04.2020) // С3 РФ. 1998. N 31. В качестве примера, в соответствии со ст. 3823. Приказ Минсельхоза РФ от 02.02.2004 г. N 75 «Об утверждении Методических рекомендаций по бухгалтерскому учету государственных субсидий и других видов государственной помощи в сельскохозяйственных организациях» (вместе с «Отраслевыми Методическими рекомендациями по бухгалтерскому учету в сельскохозяйственных организациях государственных субсидий и других видов государственной помощи») субсидия - бюджетные средства, предоставляемые бюджету другого уровня бюджетной системы Российской Федерации, физическому или юридическому лицу на условиях долевого финансирования целевых расходов (компенсация части затрат на приобретение минеральных удобрений, средств химической защиты растений, дотации на производство продукции растениеводства и животноводства, страхование сельскохозяйственных культур и т.п.).

4. Федеральный закон от 25.02.1999 г. N 39-Ф3 (ред. от 02.08.2019) «Об инвестиционной деятельности в Российской Федерации, осуществляемой в форме капитальных вложений»// СЗ РФ. 1999. N 9. Ст. 1096.

5. Терехова Е.В. Формы инвестиционной деятельности государства (финансово-правовой аспект) // Вопросы экономики и права. 2013. N 4. С. 27-34. 
6. Постановление Правительства РФ от 14.08 .2013 г. N 699 (ред. от 30.12.2018) «О проведении расчетов и перечислении средств в связи с формированием и использованием дополнительных нефтегазовых доходов федерального бюджета, средств Фонда национального благосостояния, а также о признании утратившими силу отдельных актов Правительства Российской Федерации» (вместе с «Правилами проведения расчетов и перечисления средств в связи с формированием и использованием дополнительных нефтегазовых доходов федерального бюджета и средств Фонда национального благосостояния») // С3 РФ. 2013. N 34. Ст. 4434.; Постановление Правительства РФ от 19.01.2008 г. N 18 (ред. от 30.12.2018) «О порядке управления средствами Фонда национального благосостояния» (вместе с «Требованиями к финансовым активам, в которые могут размещаться средства Фонда национального благосостояния») // С3 РФ. 2008. N 4. Ст. 270.; Постановление Правительства РФ от 05.11.2013 N 990 (ред. от 05.03.2018) «О порядке размещения средств Фонда национального благосостояния в ценные бумаги российских эмитентов, связанные с реализацией самоокупаемых инфраструктурных проектов» (вместе с «Правилами размещения средств Фонда национального благосостояния в ценные бумаги российских эмитентов, связанные с реализацией самоокупаемых инфраструктурных проектов») // СЗ РФ. 2013. N 45. Ст. 5824.

7. Федеральным законом от 17.05.2007 г. N 82-Ф3 «О государственной корпорации развития «ВЭБ.РФ» [СЗ РФ. 2007. N 22. Ст. 2562.

8. Приказ Минфина России от 16.10 .2000 г. N 92н (ред. от 04.12.2018) «Об утверждении Положения по бухгалтерскому учету «Учет государственной помощи» ПБУ 13/2000» // «Финансовая газета», N 47, 2000.

9. Ярушкина Н.А., ЗеленинаЕ.С. Роль финансирования в управлении инвестиционными проектами // Проблемы экономики и управления строительством в условиях экологически ориентированного развития.2016.- С. 490.

10. Налоговый кодекс Российской Федерации (часть первая)» от 31.07 .1998 г. N 146-Ф3 (ред. от 01.04.2020) // С3 РФ. 1998. Ст. 3824.; «Налоговый кодекс Российской Федерации (часть вторая)» от 05.08.2000 г. N 117-ФЗ (ред. от 01.04.2020) (с изм. и доп., вступ. в силу с 18.04.2020) // СЗ РФ. 2000. N 32. Ст. 3340.

11. Михайлов П.А.Нормативно-правовая база в области финансирования инвестиционных проектов государственно-частного партнерства // Новая наука: Опыт, традиции, инновации. - 2016. - № 5-1 (83).C. 168.

12. Ярушкина Н.А., ЗеленинаЕ.С. Роль финансирования в управлении инвестиционными проектами // Проблемы экономики и управления строительством в условиях экологически ориентированного развития.2016.- C. 491.

13. Закон Республики Саха (Якутия) от 07.11.2013 г. 1231-3 N 17-V «О налоговой политике Республики Саха (Якутия)» (принят постановлением ГС (Ил Тумэн) РС(Я) от 07.11.2013 3 N 18-V) из информационного банка «Республика Саха (Якутия)» // «Ил Тумэн», N 45, 15.11.2013.

14. Решение Совета депутатов городского поселения Люберцы Люберецкого муниципального района МО от 07.06.2012 г. N 229/5 «Об утверждении Положения об участии города Люберцы в муниципально-частном партнерстве» // «Люберецкая газета», N 22, 22.06.2012.

15. Боровикова Е.В. Применение специальных налоговых режимов в договорах государственно-частного партнерства в Российской Федерации // Финансы и кредит. 2012. № 38 (518). URL: https://cyberleninka.ru/ article/n/primenenie-spetsialnyh-nalogovyh-rezhimov-v-dogovorah-gosudarstvenno-chastnogo-partnerstva-vrossiyskoy-federatsii.

16. Шарапов В.В. О государственном (муниципальном) частном партнерстве // СПС КонсультантПлюс. 2016. 